
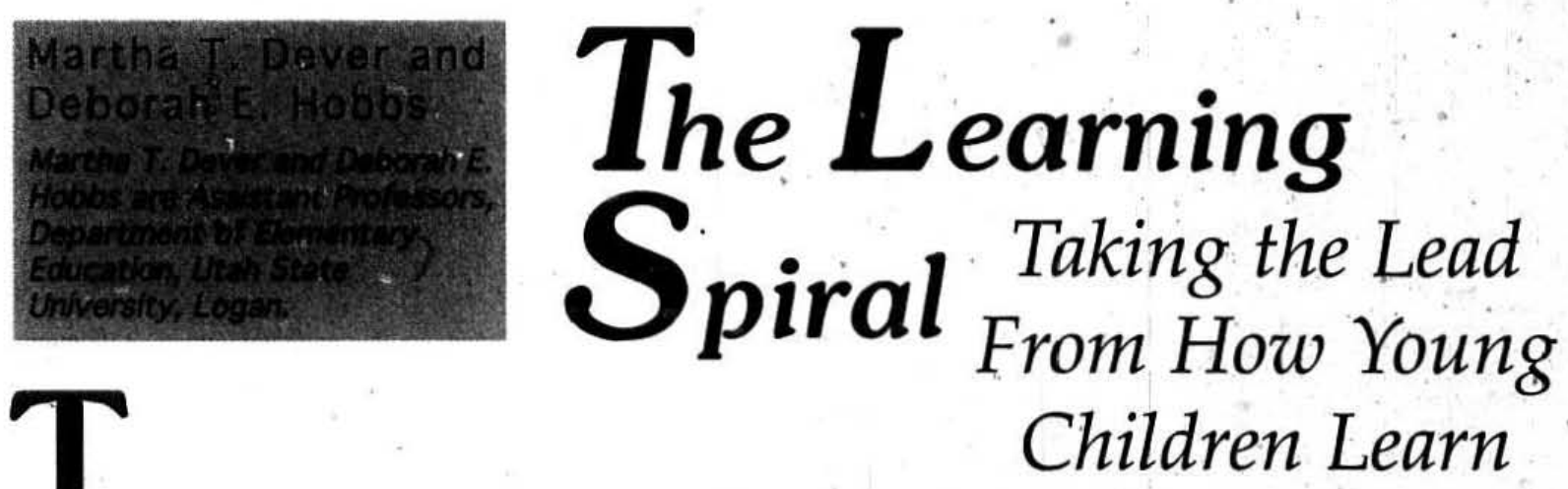

he questions at right, asked by 2 nd-graders, launch a scientific inquiry about owls. As the 7-year-olds investigate stuffed owl specimens, they express their need to know. Some children continue to stroke the owls' feathers, touch a sharp claw, and ask questions about the mouth, while others immediately, turn to printed materials to clarify their questions. This new experience with owls ignites the children's sense of wonder, and the intrinsically motivated scientific inquiry begins.

Another group of 7-year-olds are also studying owls in a science unit. These students, however, sit at their desks attending to a textbook assignment. The room is fairly quiet, except for occasional trips to the pencil sharpener or the bathroom. The motivation for these learners is externally supplied by the teacher. Consequently, this learning experience is a solitary one.

The scenarios above exemplify the classic tension between student-centered and teacher-centered learning environments. This tension is not new. In the 17th and 18 th centuries, education pioneers like Comenius and Rousseau (Ornstein \& Levine, 1993) suggested that young children learn best through active exploration of their world. In the early 2uth century, Dewey (1938) promoted a view of the environment as a source of real and educative experiences.

In the 1980s, Goodlad (1984) called for "teaching designed to involve students more meaningfully and actively in the learning process" (p. 271). Other researchers (Miller \& Bizzell, 1984; Schweinhart \& Weikart, 1988; Tunnell \& Jacobs, 1989) reported that a child-centered learning environment promotes achievement more than didactic, teacher-directed programs.

The call for developmentally appropriate practice also supports childcentered environments. Developmental appropriateness is two-fold. First, age appropriateness acknowledges the predictable sequences of growth and change, which provide a framework for teachers to prepare learning experiences. Second, individual appropriateness acknowledges that each child is a unique person with an individual pattern and timing of growth (Bredekamp, 1987). Hence, a developmentally appropriate curriculum must:

- provideforallareas of achild'sdevelopment throughtheintegratedcurriculum

- be based on teachers' observations and recordings of each child's special interests and developmental progress

- emphasize learning as an interactive process

- offer learning experiences and materials that are concrete and relevant to the lives of children

- provide for a wider range of developmental interests and abilities than the chronological age range of a group would suggest

- provide a variety of activities and materials that increase in difficulty and complexity as the children develop understanding skills. (Bredekamp, 1987, pp. 3-4)

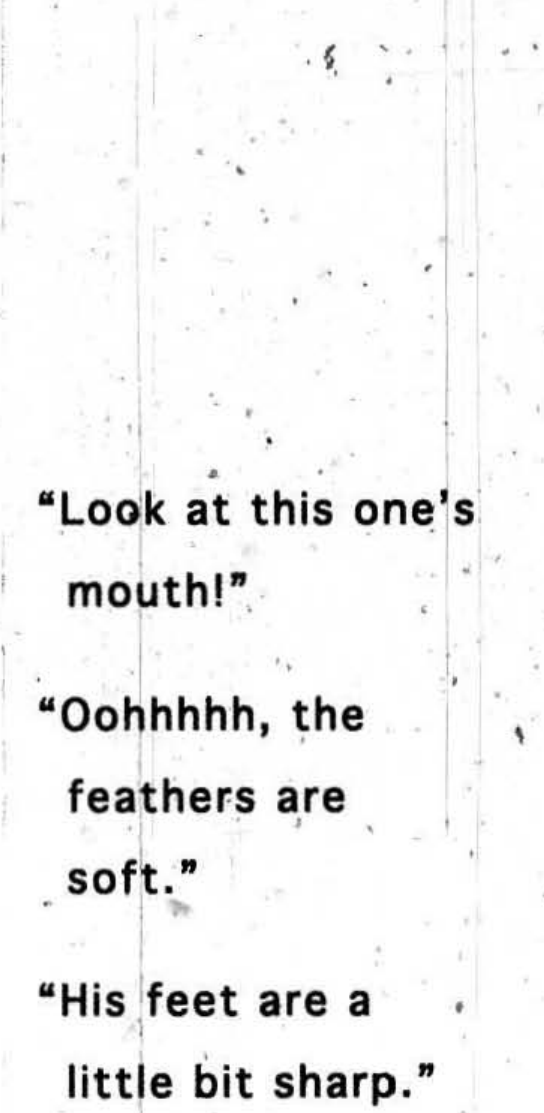

"What kind of owls are these?". 


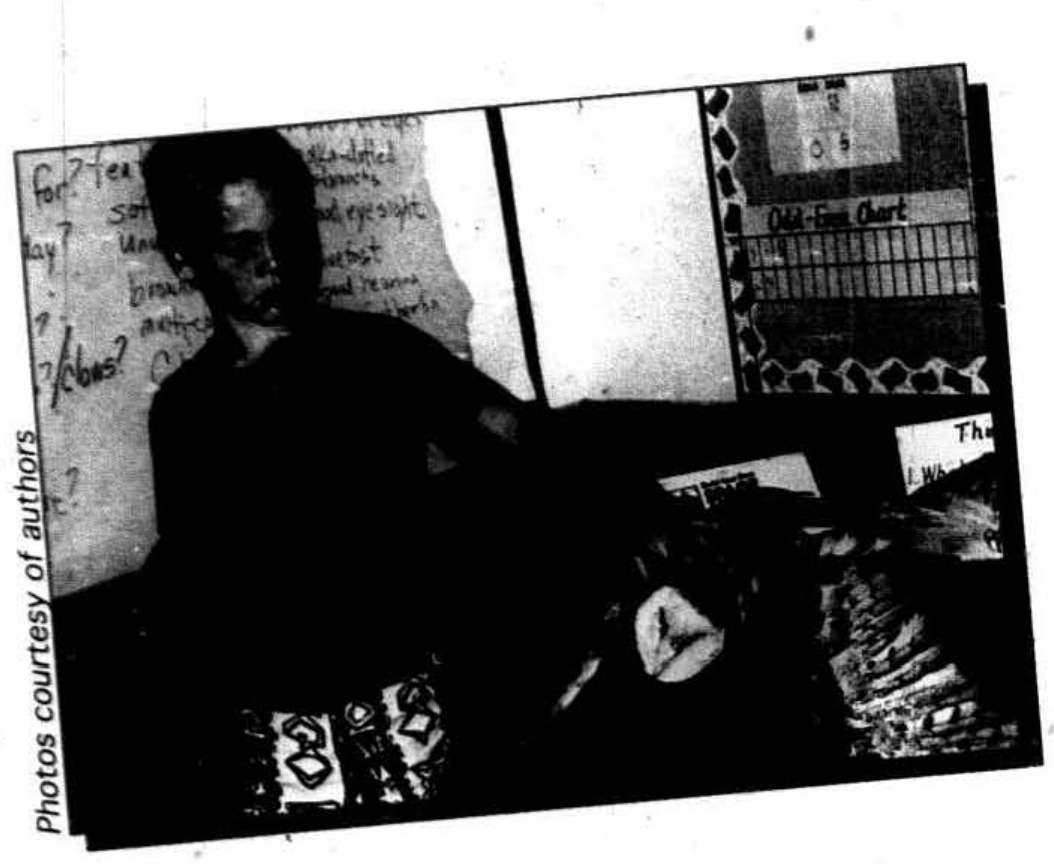

\section{Theory Into Practice}

As we rejoin the curious 7-year-olds, we now notice that Lisa, while holding a book, is looking from the owl specimens to the book. She turns the pages and then studies the specimens again. "That's a barn owl,"-Lisa eventually declares. "See, they look just like this," she adds, as she holds up a full-page photo of a barn owl for her peers to view.

To continue engaging the children in the topic of owls, we ask them to describe the owl specimens for us. "They're brownishgold," Sam shares, adding as an afterthought, "and they're long-feathered." "They have sharp, pointy feet," Heather comments.

To further ignite their curiosity, we continue engaging the children's sense of wonder by implementing a K-W-L (Ogle, 1986). The K-W-L strategy invites learn-

Despite the mounting theory and research that support a child-centered learning environment, it appears that this instructional approach seldom takes a firm foothold in America's classrooms. During 25 years as an administrator and researcher, Cuban (1984) discovered a uniformity in classroom practice: "I found evidence of a seemingly stubborn continuity in the character of instruction despite intense reform efforts to move classroom practices toward instruction that was more student-centered" (p. 2). Unfortunately, when Cuban (1993) revisited his previous study nearly a decade later, he noted that "the tradition of teachercentered instruction continues to dominate both elementary and secondary classrooms" (p. 272).

Two questions, then, face educators of young children: 1) What does developmentally appropriate, childcentered practice look like? and 2) How do teachers create a developmentally appropriate, child-centered learning environment? This article will offer possible answers to these two questions by using science instruction as the vehicle and focusing on 2nd-grade learners. First, the authors take the reader into an actual 2nd-grade classroom where developmentally appropriatechild-centeredness was field-tested and achieved in a scientific investigation. Second, the authors explain the Learning Spiral (Hobbs, Dever, \& Tadlock, 1995), which provided a vehicle for creating developmentally appropriate practice in the classroom. The Learning Spiral-which comprises the stages engage, investigate, share, and assess-was designed by the authors and a colleague (Hobbs, Dever, \& Tadlock, 1995) to provide teachers with a framework for thinking abcut instructional planning in a way that is consistent with how young children learn best. ers to help set the direction of the study, beginning as children share what they know (K) about a topic. When these ideas have been exhausted, the learners generate a list of questions or things they want $(\mathrm{W})$ to know about the topic. Finally, after a varietỹ of learning experiences, the learners come together to share what they have learned $(\mathrm{L})$.

As the 2nd-graders share what they know about owls, it is clear that some were new to the study of owls, while others possessed previous knowledge. All of the students displayed a sense of wonder about owls, as is evident in their questions.

"How fast do they fly?" is Sam's burning question, to which he adds, "and where do they live?"

"How much do they eat?" wonders Rebecca.

"Yeah, and what do they eat?" adds David.

"They eat mice and bats," Helen shares, confidently.

Helen's comment provides a perfect segue to our plan for the day, which includes an investigation of owl pellets. We ask, "If they eat mice and bats, what happens to the bones? Do you think they spit them out like a watermelon seed? Or, do you think they eat

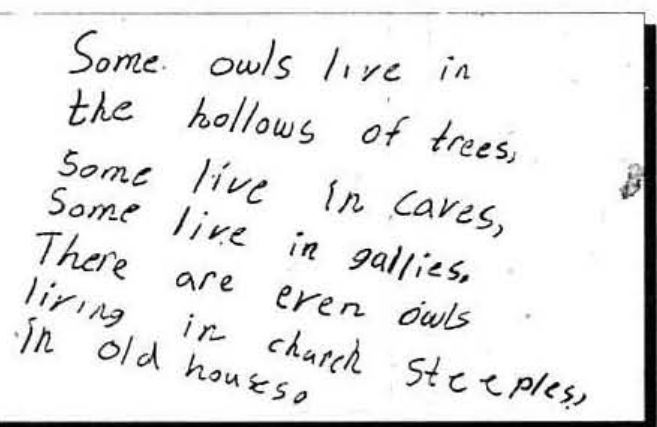

Figure 1 


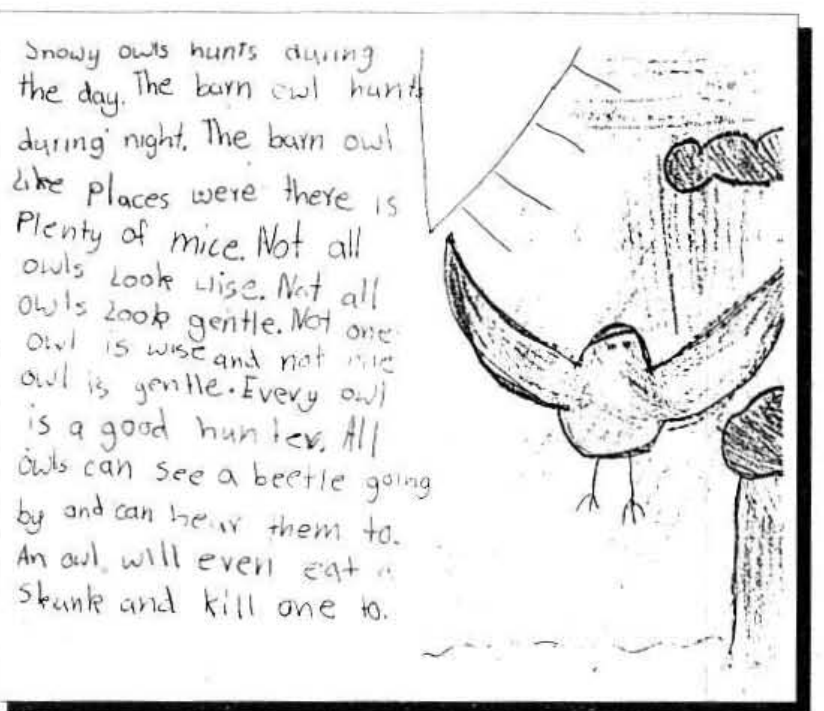

Figure 2

around them like we eat a piece of chicken?"

"No," Eric corrects, "that's the owl pellets. Their stomachs makebonesand hair intoaball and they throw'emup."

"Satisfied that the children are formulating questions they find important, we deem it time to investigate owls. To facilitate the children's investigations, we gather several nonfiction trade books about owls and provide each child with a booklet simply labeled "Owl Notes." Within the pages of inviting literature, these curious 7-year-olds will find and record answers. Each child selects a book or two that looks interesting, and then finds a comfortable spot in which to read. There is a sense of anticipation and excitement that suggests these students welcome the task at hand. Their job is to use their developing reading and writing skills to satisfy their need to know.

Each literature exploration begins as a solitary activity. As they discover interesting things, however, the children begin sharing their new understandings. Jeff, for example, shows Scott a picture of a snowy owl, which generates an investigation of this particular owl for both children. Their shared, yet individual, investigations are facilitated by adults' questions, such as: "Isn't that a unique looking owl? I wonder where it lives." Upon learning that the snowy owl lives in the Canadian tundra, Jeff walks over to the globe to pinpoint exactly where snowy owls are found. Figures 1 and 2 depict the owl notes that Jeff and Scott collected, which suggest the similar, yet different, results of their investigations.

The children's investigations of the literature culminate as the class comes together to share what they have learned. As we chart their new knowledge, the individual nature of the children's interests is quite apparent. Some have gathered datà on the sizes of various owlsfrom the great gray owl, which has a wing span of 69 inches, to the elf owl, which can fit into a teacup. Others have limited their reading to a particular type of owl.

During the process of charting the new understandings, we ask if anyone has learned anything new about owl eyes or owl pellets, two areas we had invited the children to investigate earlier. Our invitation to find out about owl eyes fell flat; not one learner has been interested in investigating that topic. And only one student, David, accepted our invitation to locate information on owl pellets. Based on our exfensive experience with children, however, we were confident that the entire class would be interested in an investigation of real owl pellets. It is one thing to read about how owls eat rodents and other animals and then regurgitate the bones, and quite another to complete a firsthand study of the resulting owl pellets.

We organize the children into pairs, each of which is provided with an owl pellet and a chart. Based on the results of our group sharing, the students expect to find hair and various bones in their pellets. The chart guides the learners as they compare and classify the bones they find, a task that captures everyone's interest. As the various bones are identified, each pair of children classifies and counts them (Figure 3 ).

The children's final task is creating a graph to depict the number of bones found among all of the pellets. To facilitate this process, we provide a similar, larger chart. Then, each pair of students places the number of sticky notes representing their findings in the proper column. The students find a total of 237 bones!

\section{Reconstructing the Learning Spiral} As mentioned earlier, the primary objective of the Learning Spiral is to assist children in using their developing skills as tools for understanding their social and physical worlds. Learning activities build on individual-learners' unique prior experiences, and acknowledge the individual nature of developing .reading, writing, mathematical, and higher-order thinking skills.

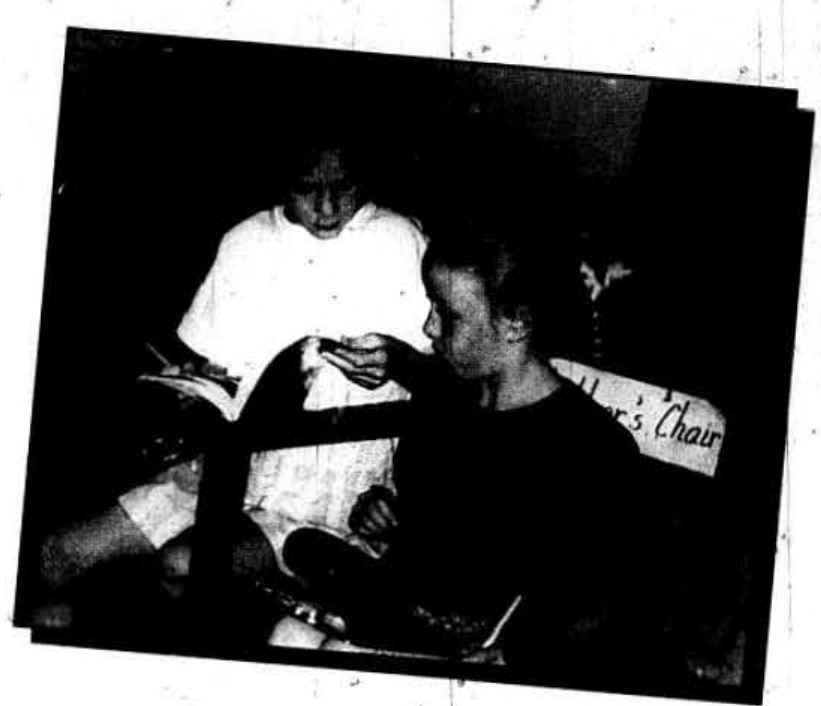




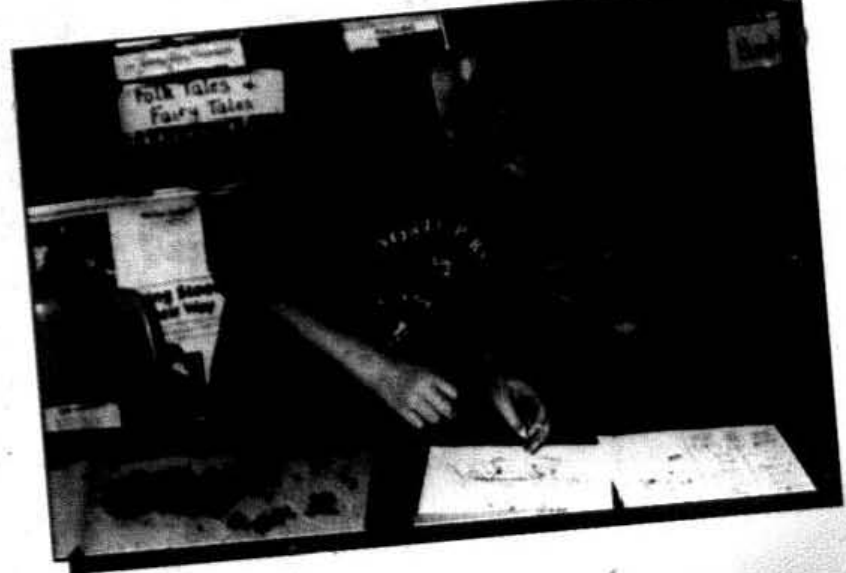

The learning activities just described encompass three generalizations or "Big Meanings": owls are nocturnal birds, not all food is digested, and different animals have different digestive systems. These Big Meanings constitute the teacher's agenda for helping students make sense of their world. The students, however, acquire knowledge beyond these Big Meanings, based on their particular interests. Thus, the teacher and the students create the curriculum together.

Furthermore, more than science content learning has occurred. The owl unit invited the learners to use their process skills, providing them with substantive, interesting content to read, write, problem solve, and think about (Hobbs, Dever, \& Tadlock, 1995). The literature provided a rich, in-depth source of information. The children took notes on things of interest, and later wrote about them in their journals, which trained their writing skills. They relied on their developing math skills as they collected and organized data on the types of bones found in the owl pellets. Still other skills were developed: Jeff and Scott enhanced their knowledge of geography, for example, when they located the natural home of the snowy owl. This approach values a sense of wonder, and facilitates the development of crucial process skills.

In reconstructing this learning experience, it is evident that the Learning Spiral is not linear, but rather is recursive (Hobbs, Dever, \& Tadlock, 1995). Recall that the 2 nd-graders were presented with a unique experience as they arrived at school-the opportunity to explore and discuss the stuffed owl specimens. The primary intent of this initial activity was to engage the learners in the stady of owls. Closer reflection on this activity highlights the recursive nature of the Learning Spiral, because the children were also investigating and sharing as they touched, observed, and discussed the owl specimens. As they shared thoughts and ideas, the children reengaged in individual investigations.

The K-W portion of the K-W-L served primarily as an engagement activity, but also encompassed some sharing when the class created a list of interesting things they wanted to know. Cne student's questions might help others generate their own questions. The teacher can pose some questions, as well. In this scenario, for example, we purposefully raised questions about the unique appearance of the owls' eyes, offering an invitation to investigate (which no one accepted). Another of our invitations focused on the owl pellets and was accepted readily by all-students, once they were presented with real owl pellets.

Two activities were designed primarily as investigation experiences: reading the trade books, and dissecting the owl pellets. But other elements of the Learning Spiral emerged as the children investigated the trade books and pellets. Recall how solitary reading often led to group reading and discussion. Jeff's interest in the snowy owl was soon shared by Scott, for example, and they began to seek information together. This applies also to both the $\mathrm{L}$ component of the K-W-L and the class graphing activity. Both were sharing activities that encompassed the other components of the Learning Spiral.

Opportunities for assessment (by teachers and students) were embedded in each component of the Learning Spiral. As we listened to comments and questions, we were able to determine, to some degree, a student's prior understandings. We kept anecdotal records documenting their developing literacy and mathematical skills, and we created and assessed written artifacts.

Perhaps more important, the students had many opportunities for self-assessment. After listening, commenting, and raising questions during the engagement activities, for example, each learner set his or her personal direction for investigation, which demonstrates that a learner constantly self-assesses both prior understandings and interests.

\section{Conclusion}

Earlier, this article raised the questions "What does developmentally appropriate, child-centered practice look like?" and "How do teachers create a developmentally appropriate, child-centered learning environment?" In the context of a 2nd-grade scientific inquiry about owls, we painted a picture of a developmentally appropriate classroom. In this classroom, learning was a collaboration between teacher and learners. While the teacher's agenda-the Big Meanings-for the experience was met, the learners also had opportunities to add to the teacher's agenda. Students used reading, writing, data gathering, and mathematical and spatial skills to help them satisfy their curiosity. Process and content were mutually important.

The Learning Spiral helped create such a learning environment. The authors contend that such a tool will enable primary grade teachers to embrace a more childcentered instructional approach. Of course, the idea of a learning cycle is not new. Partially grounded in the 


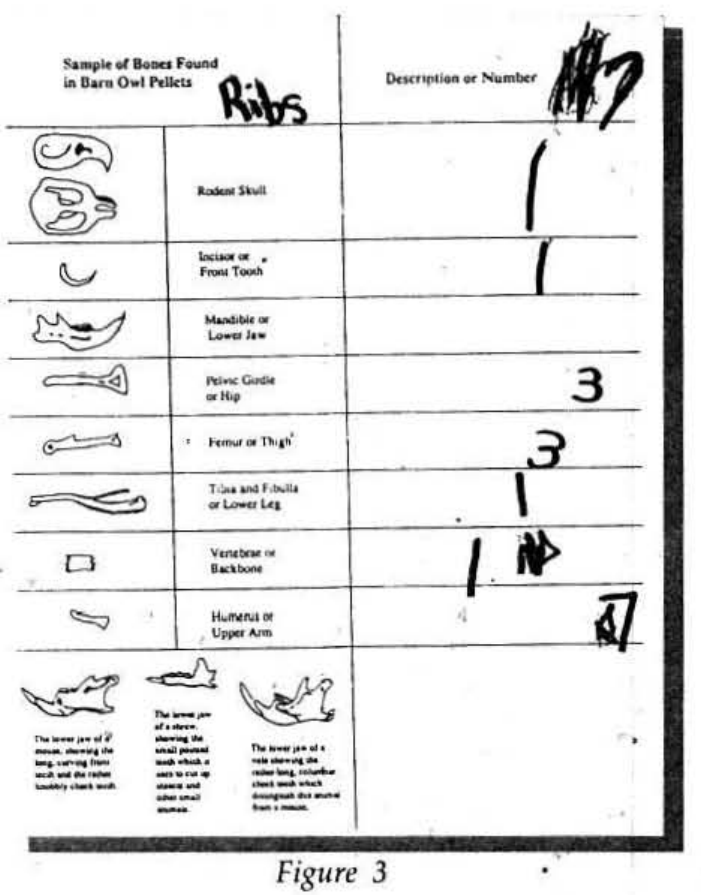

experiential learning theories of Piaget (1964) and Dewey (1938), cycles that frame the learning process have been developed by researchers such as Karplus and Thier (1967) and Kolb (1984). While researchers found that students whose school experiences encompass the learning cycle approach demonstrate gains in achievement, such research has focused primarily on secondary science (Purser \& Renner, 1983; Saunders \& Shepardson, 1987; Schneider \& Renner, 1980).

Two characteristics differentiate the Learning Spiral from earlier learning cycles (Hobbs, Dever, \& Tadlock, 1995). First, consistent with learning cycles, the Learning Spiral provides a framework for integrating all academic disciplines in an elementary setting. The Learning Spiral, however, emphasizes process skill development and content learning equally. Learning experiences designed to teach reading, writing, and mathematics consume a large portion of the day in primary level classrooms. The authors believe that children will be more intrinsically motivated to use and develop these skills if the core of their school experiences contains interesting events, objects, and living things from the "real world." While we would not deny the occasional need for teacher-directed lessons (a minilesson on the use of punctuation in a letter of inquiry, for example), we argue that the larger portion of the elementary school day should encompass engaging students' curiosities and providing materials and assistance for them to investigate, share, and assess (Hobbs et al., 1995).

As both teachers and students assess learning, new invitations will emerge and students will re-engage in the Learning Spiral. This highlights the second unique characteristic of the Learning Spiral-its recursive nature. Learning is not an event, but rather a process in which multiple components come into play at any time. To break the components of learning into discrete events is to violate the dynamic nature of learning and ignore the interaction of engagement, investigation, sharing, and assessment.

Young children have acquired language, mobility, and many conceptual understandings - all through the context of daily living, not formal instruction. Dewey (1938) posited that school and life should be one and the same, in the sense that learners learn by doing. Hence, instructional design in the primary grades should be modeled after what learners do naturally in the real world. The Learning Spiral can help teachers to think about this natural learning process and to view children as intrinsically motivated to participate in their world.

\section{References}

Bredekamp, S., \& Copple, C. (Eds.). (1987): Developmentally appropriate practice in early childhood programs serving childen from birth through age 8 (Rev. ed.). Washington, DC: National Association for the Education of Young Children.

Cuban, L. (1984). How teachers taught: Constancy and change in American classrooms 1890-1980. New York: Longman.

Cuban, L. (1993). How teachers taught: Constancy and change in American classrooms 1890-1980. New York: Teachers College Press.

Dewey, J. (1938). Experience and education. New York: Macmillan. Goodlad, J. I. (1984). A place called school: Prospects for the future. New York: McGraw-Hill.

Hobbs, D. E., Dever, M. T., \& Tadlock, M. (1995). A curriculum planning tool: The learning spiral. Transescence: The Journal on Emerging Adolescent Education, 23(2), 28-33.

Karplus, R., \& Thier, H. D. (1967). A new look at elementary school science. Chicago: Rand McNally and Company.

Kolb, D. A. (1984). Experiential learning: Experience as the source of learning and development. Englewood Cliffs, NJ: Prentice-Hall, Inc.

Miller, L. B., \& Bizzell, R. P. (1984). Long-term effects of four preschool programs: 9 th and 10th grade results. Child Development, 55, 1570-1587.

Ogle, D. M. (1986). K-W-L: A teaching model that develops active reading of expository text. The Reading Teacher, 39, 564-570.

Ornstein, A. C., \& Leyine, D. U. (1993). Foundations of education (5th ed.). Boston: Houghton Mifflin.

Piaget, J. (1964). Part I: Cognitive development in children: Piagetdevelopmental learning. Journal of Research in Science Teaching, 2, 176-186.

Purser, R. K., \& Renner, J. W. (1983). Results of two tenth-grade biology teaching procedures. Science Education, 67(1), 85-98.

Saunders, W. L., \& Shepardson, D. (1987). A comparison of concrete and formal science instruction upon science achievement and reasoning ability of sixth grade students. Journal of Research in Science Teaching, 24(1), 39-51.

Schneider, L. S., \& Renner, J. W. (1980). Concrete and formal teaching. Journal of Research in Science Teaching, 17(6); 503-517.

Schweinhart, L. J., \& Weikart, D. P. (1988). Education for young children living in poverty: Child-initiated learning or teacherdirected instruction? The Elementary School Journal, 89(2), 213225.

Turnell, M. O., \& Jacobs, J. S. (1989). Using real books: Research findings on literature based reading instruction. The Reading Teacher, 42(7), 470-477. 